\title{
EDITORIAL Sleep and Anesthesia
}

\author{
Matthias Eikermann*
}

\author{
Department of Anesthesia, Critical Care, and Pain Medicine Massachusetts General, Hospital and Harvard Medical \\ School, 55 Fruit Street, Boston
}

The supplement within this volume of The Open Anesthesiology Journal focuses on emerging links between sleep and anesthesia. Sleep is the natural periodic suspension of consciousness during which the powers of the body are restored. General anesthesia is a drug-induced, reversible condition comprised of five behavioral states: hypnosis (loss of consciousness), amnesia, analgesia, and immobility (no movement in response to pain stimuli), and hemodynamic stability with control of the stress response [1]. Anesthesia and sleep are visibly different [2], and many researchers are in the process of gathering interesting new information on the similarities and differences of the mechanisms leading to anesthesia and sleep (for review see Brown and coworkers [3]). Temporary loss of consciousness as well as a modulation of brainstem autonomic function represent a clinically meaningful common ground of sleep and anesthesia.

Upper airway dilator muscle tone decreases as the transition from wakefulness to sleep and anesthesia is been made

[4], which can lead to hypopnea and apnea [4]. Obstructive sleep apnea (OSA) is a common disorder affecting $2-26 \%$ of the general population depending on sex, age and the definition of criteria. It has important sequelae such as hypertension, myocardial infarction, and stroke [5-8], and patients with OSA are suggested to be at increased risk to develop serious perioperative complications, particularly during the post-operative period [9-11]. The reduction of post-operative complications for patients with OSA has been a recent goal of the Joint Commission of the American Hospital Association (JCAHO). This issue of the Open Anesthesiology Journal comprises important information on how to improve safety of OSA patients during anesthesia.

Frances Chung summarizes the current concepts on how to make diagnosis of OSA in the perioperative context [12]. This is important, because it is challenging to make diagnosis of sleep disordered breathing in patients while they are asymptomatic, which is typically the case during wakefulness. Tom Ebert and coworkers [13] focus on the relation between morbid obesity and OSA - Obesity is an epidemic with major health consequences, and obesity and OSA are related: about $50 \%$ of patients with morbid obesity have OSA. Both, obesity and OSA have important

*Address correspondence to this author at the Department of Anesthesia, Critical Care, and Pain Medicine Massachusetts General, Hospital and Harvard Medical School, 55 Fruit Street, Boston, MA; Tel: 617-643-4408; Fax:617-726-5985; E-mail: meikermann@partners.org implications with regard to perioperative safety of patients presenting with these diseases. The studies of Karan and Koo are focused on possible perioperative therapeutic implications of OSA. Continuous Positive Airway Pressure (CPAP) is the golden standard for treatment of patients with OSA, but the method has limitations in the perioperative period. Karan and co-workers summarize the considerations regarding perioperative implementation of CPAP [14]. Opioids are the first line treatment of severe postoperative pain, but opioids decrease respiratory drive and their use is associated with serious postoperative respiratory complications in patients susceptible to their side effects. Koo and coworkers summarize the pathophysiology of opioidinduced side effects in the perioperative context [15]. The knowledge on how to treat patients with OSA or those at high risk of an (unidentified) OSA is evolving. Peter Gay [16] concludes this special issue by summarizing his vision of the future of our field: Which studies need to be conducted to improve perioperative safety of patients with OSA?

I extend a sincere thank you to all the authors for their contributions to this supplement on sleep and anesthesia and also my gratitude to the reviewers for their conscientiousness approach and pertinent comments on the manuscripts.

\section{REFERENCES}

[1] Evers ASMC. Cellular and molecular mechanisms of anesthsia. In: Clinical Anesthesia. In: Barash PG, Cullen BF, Stoelting RK, Eds. New York: Lippincott, Williams, \& Wilkins 2006; pp. 111-32.

[2] Chamberlin NL, Eikermann M. This is no humbug: anesthetic agent-induced unconsciousness and sleep are visibly different. Anesthesiology 2010; 113: 1007-9.

[3] Brown EN, Lydic R, Schiff ND. General anesthesia, sleep, and coma. N Engl J Med 2010; 363: 2638-50.

[4] Eikermann M, Fassbender P, Zaremba S, et al. Pentobarbital dosedependently increases respiratory genioglossus muscle activity while impairing diaphragmatic function in anesthetized rats. Anesthesiology 2009; 110: 1327-34.

[5] Peppard PE, Young T, Palta M, et al. Prospective study of the association between sleep-disordered breathing and hypertension. N Engl J Med 2000; 342: 1378-84.

[6] Nieto FJ, Young TB, Lind BK, et al. Association of sleepdisordered breathing, sleep apnea, and hypertension in a large community-based study. Sleep Heart Health Study. JAMA 2000; 283: 1829-36.

[7] Faccenda JF, Mackay TW, Boon NA, et al. Randomized placebocontrolled trial of continuous positive airway pressure on blood pressure in the sleep apnea-hypopnea syndrome. Am J Respir Crit Care Med 2001; 163: 344-8.

[8] Yaggi HK, Concato J, Kernan WN, et al. Obstructive sleep apnea as a risk factor for stroke and death. N Engl J Med 2005; 353: 2034-41. 
[9] Meoli AL, Rosen CL, Kristo D, et al. Upper airway management of the adult patient with obstructive sleep apnea in the perioperative period--avoiding complications. Sleep 2003; 26: 1060-5.

[10] Loadsman JA, Hillman DR. Anaesthesia and sleep apnoea. Br J Anaesth 2001; 86: 254-66.

[11] Hillman DR, Loadsman JA, Platt PR, et al. Obstructive sleep apnoea and anaesthesia. Sleep Med Rev 2004; 8: 459-71.

[12] Chung F. Screening for obstructive sleep apnea syndrome in the preoperative patients. Open Anesth J 2011; 5: 7-11.
[13] Ebert TJ, Novalija J. Morbid obesity and obstructive sleep apnea: the challenging link. Open Anesth J 2011; 5: 19-22.

[14] Karan S, Black S, Mouton F. Perioperative implementation of continuous positive airway pressure: a review of the considerations. Open Anesth J 2011; 5: 14-18.

[15] Koo CY, Eikermann M. Respiratory effects of opioids in perioperative medicine. Open Anesth J 2011; 5: 23-24.

[16] Gay PC. What future studies are needed for obstructive sleep apnea patients undergoing surgery? Open Anesth J 2011; 5: 12-13.

(C) Matthias Eikermann; Licensee Bentham Open.

This is an open access article licensed under the terms of the Creative Commons Attribution Non-Commercial License (http://creativecommons.org/licenses/by$\mathrm{nc} / 3.0 /$ ) which permits unrestricted, non-commercial use, distribution and reproduction in any medium, provided the work is properly cited. 